\title{
Predicting a dissociative disorder from type of childhood maltreatment and abuser- abused relational tie
}

\author{
CHRISTA KRÜGER, MBBCh, MMed(Psych), MD, FCPsych(SA) \\ Department of Psychiatry, University of Pretoria; and Weskoppies Hospital, Pretoria, \\ South Africa
}

LIZELLE FLETCHER, BCom(Econometrics), Honours(Mathematical Statistics), MSc(Mathematical Statistics), PhD(Statistics)

Department of Statistics, University of Pretoria, South Africa

\author{
Corresponding author: Prof Christa Krüger \\ Address: Department of Psychiatry, University of Pretoria, Weskoppies \\ Hospital, Private Bag X113, Pretoria, 0001, South Africa \\ Tel: +27 123199741 \\ Fax: +27123199617 \\ E-mail: christa.kruger@up.ac.za
}

\section{Postal mailing addresses of authors:}

Prof Christa Krüger: Department of Psychiatry, University of Pretoria, Weskoppies Hospital, Private Bag X113, Pretoria, 0001, South Africa

Dr Lizelle Fletcher: Department of Statistics, University of Pretoria, Private Bag X20, Hatfield, 0028, South Africa

Grant support: This research was funded by grants from the South African National Research Foundation, as well as the Department of Psychiatry and Faculty of Health Sciences of the University of Pretoria. These sponsors had no role in the study design; in the collection, analysis and interpretation of data; in the writing of the report; or in the decision to submit the article for publication.

Acknowledgements: The authors are grateful to Mrs J Sommerville of the Department of Statistics, University of Pretoria for her assistance with electronic data management and statistical analyses; to Mr BB Versfeld, Ms R Liprini and Ms L Meiring (research assistants in the Department of Psychiatry, University of Pretoria) for their assistance with questionnaire-based data collection and data management; and to the patients for their willingness to participate in this research study.

The results of this study have not been presented before. 


\section{ABSTRACT}

We investigate the types of childhood maltreatment, and abuser-abused relational ties that best predict a dissociative disorder (DD). Psychiatric in-patients $(n=116$; mean age $=35 ; \mathrm{F}: \mathrm{M}=1.28: 1)$ completed measures of dissociation and trauma. Abuse type and abuser-abused relational ties were recorded in the Traumatic Experiences Questionnaire. Multidisciplinary team clinical diagnosis or administration of the SCID-D-R to high dissociators confirmed DD diagnoses. Logit models described the relationships between abuser-abused relational tie and the diagnostic grouping of patients, DD present $(n=16)$ or DD absent $(n=100)$. Fisher's exact tests measured the relative contribution of specific abuse types. There was a positive relationship between abuse frequency and the presence of DD. DD patients experienced more abuse than patients without DDs. Two combinations of abuse type and relational tie predicted a DD: childhood emotional neglect by biological parents/siblings and later emotional abuse by intimate partners. These findings support the early childhood etiology of DDs and subsequent maladaptive cycles of adult abuse. Enquiries about childhood maltreatment should include a history of emotional neglect by biological parents/siblings. Adult emotional abuse by intimate partners should assist in screening for DDs.

Keywords: Dissociative disorders; childhood maltreatment; emotional neglect; emotional abuse; abuser-abused relational ties; biological parents/siblings; intimate partners 


\section{INTRODUCTION}

The etiological role of complex, chronic, relational early childhood maltreatment in the development of DDs is well known (Dalenberg et al., 2012; Dorahy \& Van der Hart, 2007; Dorahy et al., 2014; Van der Hart et al., 2006). The roles of specific types of childhood maltreatment and the specific abuser-abused relational ties that place the victim at the highest risk of developing a DD are less well known.

Along with sexual and physical abuse, emotional abuse has been receiving increased attention in the literature. Emotional abuse has been associated with or may predict dissociative symptoms in various populations, including adult psychiatric patients with various diagnoses (Mueller-Pfeiffer et al., 2013), adolescent psychiatric out-patients (Sar et al., 2014), female psychiatric in-patients with posttraumatic stress disorder linked to childhood maltreatment (Haferkamp et al., 2015), patients with borderline personality disorder (Watson et al., 2006), and patients with schizophrenia spectrum disorders (Schäfer et al., 2006).

Emotional abuse has also been associated with or may predict pathological dissociative disorder (DD). Emotional abuse, sexual abuse and physical neglect are significant predictors of a DD diagnosis in women (Sar et al. 2007). A study by Simeon et al. (2001) compared patients with depersonalization disorder to healthy control

subjects and identified emotional abuse as the most significant predictor of a depersonalization disorder diagnosis.

Emotional neglect, as a facet of emotional abuse has been studied less frequently. Sar et al. (2006) demonstrated that emotional neglect (but not emotional abuse) predicted a DD diagnosis in college students. Ozcetin et al. (2009) found that emotional abuse and emotional neglect were significantly higher in women with 
pseudoseizure-type conversion disorder than in healthy controls. More recently, Kilic et al. (2014) demonstrated that childhood emotional neglect predicted somatoform dissociation in women with fibromyalgia or rheumatoid arthritis. Similarly, Vogel et al. (2009) found an association between childhood neglect and adult dissociation in schizophrenia in-patients.

In addition to abuse type, the specific abuser-abused relational ties may also predict a DD. Identifying abuser-abused relational ties can be complex. Perpetrators of childhood abuse are not always a parent or father (Ross et al., 1991; Sandberg, 2010). Where a strong relationship between DD and childhood sexual abuse was recorded, the specific relational ties are not always identified (Farley \& Keaney, 1997; Israel \& Stover, 2009). Mueller-Pfeiffer et al. (2013) found that peri- and extra-familial maltreatment, but not intra-familial maltreatment, predicted dissociative symptoms in adult psychiatric patients. Plattner et al. (2003) found significant correlations between intra-familial trauma and the presence of a DD in delinquent juveniles. Similarly, Simeon et al. (2001) found that the majority of perpetrators of emotional abuse were one or both parents.

The relationships between types of childhood maltreatment and specific abuserabused relational ties and their influence on DD have never been addressed simultaneously. Mueller-Pfeiffer et al. (2013) came close when they studied three variables simultaneously (abuse type, familial relationship and developmental stage) in relation to dissociative symptoms as measured by the DES Taxon score. We investigate the specific types of childhood maltreatment, and the associated specific abuser-abused relational ties that are the best predictors of a dissociative disorder (DD). Identifying important risk factors associated with DD may assist in screening high risk patients. 


\section{METHODS}

\section{Design}

This quantitative study forms part of a broader mixed-methods research project. The objectives included screening for patients with DDs among psychiatric in-patients; exploring differences between patients with and without DDs; describing local variations in the clinical picture of the DDs; monitoring treatment progress and outcome in patients with DDs; evaluating available local non-public-mental-health services for patients with DDs; and generating hypotheses for future research. The design and methods were described elsewhere (Krüger, 2016).

This specific cross-sectional quantitative study investigated if types of childhood maltreatment and the associated relational tie between the abused and the abuser could predict the grouping of psychiatric patients as either having or not having a DD.

\section{Setting and sampling}

This study was conducted at two clinical facilities: Weskoppies Hospital (WKH) (a specialised state psychiatric hospital in Pretoria, and an academic training hospital at the University of Pretoria) and Tshwane District Hospital (TDH) (a regional general hospital in Pretoria that renders primary level psychiatric care).

The 116 participants (58 patients from each of the two hospitals) were consecutive psychiatric admissions who fulfilled the set of inclusion and exclusion criteria. The inclusion criteria were an age of 18 years or older and the ability to read and write English sufficiently to complete self-report questionnaires. The exclusion criteria were severe neurological or general medical conditions, or severe psychiatric impairment that precluded the patient's ability to complete self-report questionnaires. 


\section{Instruments and procedures}

Participants completed the following self-report questionnaire scales: Dissociative Experiences Scale (DES) (Bernstein \& Putnam, 1986; Carlson \& Putnam, 1993); Multidimensional Inventory of Dissociation (MID) (Dell, 2006); and Traumatic Experiences Checklist (TEC) (Nijenhuis, 1999/2004). The TEC was chosen for its broad coverage of traumatic experiences (Nijenhuis, 1999/2004). Demographic and clinical data were also collected.

DD was diagnosed in 16 patients according to a combination of the following: scores of $>30$ on both the DES and MID, discussion with the relevant multidisciplinary treating team, consulting the clinical records, conducting clinical psychiatric interviews and administering the Structured Clinical Interview for DSM-IV Dissociative Disorders - Revised (SCID-D-R) (Steinberg, 1994a,b). The SCID-D-R was administered in nine cases to confirm the clinical diagnosis. The proportion of patients with a DD was $13.8 \%$ of the 116 participants.

Twelve patients who had scores of $>30$ on both the DES and MID were lost to follow-up after their discharge from hospital. The reasons were non-functional mobile phone numbers or relocations; and two patients that declined future contact after the questionnaire scales. The diagnosed proportion of patients with a DD in this study could have been greater if these lost-to-follow-up patients had been fully assessed.

\section{Analysis}

The scale scores between patients with and without a DD were compared using T-tests for two independent samples.

Logit models using TEC data were constructed to identify the significant abuserabused relational tie predictors of a DD diagnosis. Degrees of association between 
abuser-abused relational tie and a diagnosis of a DD were investigated by compiling cross-tabulations and expected frequencies, and calculating Fisher's exact test statistics.

Thirty-four individually recorded and coded relational ties were grouped into eight categories: 1. biological parents; 2. biological siblings; 3 . other biological relatives; 4. step-parents; 5. step-siblings; 6. intimate partners; 7. friends or family friends; and 8. community members (including teacher, neighbour, colleague, manager, pastor, police officer, stranger, or a combination of various people). These eight categories were further consolidated in three categories based on closeness or accessibility to the victim. Biological parents have the greatest accessibility; other relatives (including other biological relatives, biological siblings, step-parents and stepsiblings) have intermediate accessibility; and friends/others (including friends, family friends, partners and community members) have the least accessibility. Abuser-abused relational ties for five different types of maltreatment (emotional neglect, emotional abuse, physical abuse, sexual harassment and sexual abuse) were compared between patients with and without a DD based on these three categories.

Abuser-abused relational tie associations with maltreatment were further compared between patients with and without a DD using all biological relatives (i.e., parents and other biological relatives, representing a given life-long, and often a close relationship between abuser and abused) and intimate partners (a category that emerged prominently from the raw data and that represented a usually close, yet chosen relationship between abuser and abused) as relationship categories. These distinctions were based on the idea that 'closeness' does not depend on familial bond (Schultz et al., 2003). Step-relatives, friends, family friends, school mates and community members (i.e., non-biological relational ties) were excluded from these analyses, even though 
these might be close relationships. These relationships are usually not chosen by the victim. Further comparisons between different biological relatives were conducted. All biological relatives were divided into biological parents versus other (non-parental) biological relatives to gain a deeper understanding of the role of different relational ties.

We considered if the type of abuse may predict a DD diagnosis, or alternatively play a mediating or moderating role in the relationship between the abuser-abused relational tie ('abuser relation') and the presence of a DD. The TEC's five trauma area presence scores (for emotional neglect, emotional abuse, bodily threat, sexual harassment and sexual abuse) are not only based on experiences of abuse. Specifically, the trauma area presence score for bodily threat includes a count of physical abuse experiences and a count of traumatic experiences that might be considered less relationally abusive or non-abusive, including intense pain (e.g., from an injury or surgery), threat to life from an unknown person (e.g., during a crime), and bizarre punishment. The score for bodily threat could therefore not be used as a pure indicator of physical abuse.

The focus then shifted to the raw item data of the TEC. Individual TEC item scores were also used in the analyses. Note though, that many of the individual TEC items contain information not only about the type of abuse, but also about the relational tie between abuser and abused.

\section{Ethical considerations}

Ethical clearance was granted by the Research Ethics Committee of the Faculty of Health Sciences, University of Pretoria; reference number 121/2012. Written informed consent was obtained from all participants after adequately explaining the study's 
procedures to them. Questionnaire data were collected anonymously to protect participants' identities.

\section{RESULTS}

A total of 116 patients participated in this study. Of those, $16(13.8 \%)$ were diagnosed with a DD. WKH contributed 58 patients, with six (10.4\%) DD diagnosed patients and TDH contributed 58, with ten (17.2\%) DD diagnosed patients. The 16 DD patients had a mean age of $34.3( \pm 11.1)$ years; a female:male ratio of $3: 1$; and a race distribution of $69 \%$ White, 19\% Coloured, 13\% Black, and 0\% Indian, according to the standard presentation of formal South African governmental demographic statistics. The 100 non-DD psychiatric patients had a mean age of $35.4( \pm 10.8)$ years; a female:male ratio of 1.13:1; and a race distribution of $72 \%$ White, $18 \%$ Black, $8 \%$ Coloured, and $2 \%$ Indian. The DD patients did not differ statistically from non-DD patients with respect to age, sex, or race.

According to DSM-5 (APA, 2013), 11 of the 16 DD patients (69\%) had dissociative identity disorder (DID) (three primarily of the possession type); three patients $(19 \%)$ had other specified dissociative disorder (OSDD) (chronic or recurrent mixed dissociative symptoms that approach, but fall short of, the diagnostic criteria for DID); one (6\%) had dissociative amnesia with fugue; and one (6\%) had conversion disorder / functional neurological symptom disorder (with seizures). The patient with a primary diagnosis of conversion disorder was included in the DD sample on the basis of the ICD-10's and planned ICD-11's inclusion of conversion disorders among DDs (WHO, 1992).

The majority of DD patients $(\mathrm{n}=11 ; 69 \%)$ had a comorbid mood disorder. Four DD patients (25\%) had a comorbid conversion disorder (with seizures). Two DD 
patients $(13 \%)$ had a comorbid personality disorder. The 100 non-DD patients' primary psychiatric diagnoses included mood disorders (74\%), psychotic disorders (9\%), substance-related disorders $(9 \%)$, personality disorders $(4 \%)$, cognitive disorders $(2 \%)$, anxiety disorders (1\%) and eating disorders (1\%).

DD patients had significantly higher scores on all the scales (DES, MID, TEC) administered (Table 1). All 95\% bootstrap confidence intervals indicate a significant difference between the scale scores of DD and non-DD patients $(\mathrm{p}<0.05)$.

The frequency of occurrence of maltreatment type according to different abuser relations was recorded in the TEC (Table 2). Biological parents (and to a lesser degree biological siblings and other biological relatives) were the most frequently recorded abusers among DD and non-DD patients. Emotional neglect, emotional abuse and physical abuse were predominantly associated with biological parents (Table 2). Sexual harassment and sexual abuse were equally dominantly associated with community members and biological relatives (Table 2).

DD patients recorded more maltreatment experiences than non-DD patients. All DD patients (100\%) reported emotional neglect and emotional abuse; $81 \%$ reported physical abuse; and 56\% reported sexual harassment and sexual abuse. Of the 100 nonDD patients, $71 \%$ reported emotional abuse; $67 \%$ reported emotional neglect; $50 \%$ reported physical abuse; $43 \%$ reported sexual abuse; and 32\% reported sexual harassment.

The logit model identified a significantly higher probability of a DD diagnosis in patients that experienced emotional abuse associated with abuser relation of 'intimate partner' (Table 3). The abuser relation of intimate partner was associated with a DD diagnosis for all abuse types (Table 3), but these predictions were not significant. 
TABLE 1: Comparison of scale scores between patients with and without dissociative disorders $(\mathrm{N}=116)$

\begin{tabular}{|c|c|c|c|c|c|c|}
\hline & & $\begin{array}{r}\text { Other psychiatric disorder } \\
(n=100)\end{array}$ & & $\begin{array}{r}\text { Dissociative disorder } \\
(n=16)\end{array}$ & & $\begin{array}{r}95 \% \text { bootstrap confidence } \\
\text { intervals }\end{array}$ \\
\hline & & Mean & Std Dev & Mean & Std Dev & \\
\hline $\operatorname{DES}^{1}:$ & & 22.8 & 16.8 & 52.6 & 15.7 & $(21.27 ; 38.76) *$ \\
\hline & DES taxon & 14.3 & 14.9 & 45.6 & 23.0 & $(19.31 ; 43.79) *$ \\
\hline MID & & 21.5 & 18.5 & 49.4 & 14.7 & $(19.57 ; 36.13) *$ \\
\hline TEC total score ${ }^{2}$ & & 9.5 & 4.9 & 14.0 & 5.1 & $(1.94 ; 7.48) *$ \\
\hline
\end{tabular}

\footnotetext{
${ }^{1}$ Abbreviations: DES = Dissociative Experiences Scale; MID = Multidimensional Inventory of Dissociation; TEC = Traumatic Experiences Checklist

${ }^{2}$ The TEC total score represents a count of all potentially traumatic experiences listed in items $1-29$ of the scale, which include not only experiences of abuse, but also nonabusive traumatic experiences that often form a part of everyday life, e.g., loss of a family member, or threat to life from an accident. For TEC subscores, see Table 4.
}

* statistically significantly different on bootstrap analyses at the $5 \%$ level 
TABLE 2: Frequencies of abuser-abused relational ties in various forms of maltreatment (TEC data) $(\mathrm{N}=116)$

\begin{tabular}{|c|c|c|c|c|c|c|c|}
\hline & Emotional neglect by: & All participants $(N=116)$ & $\%$ of 116 & $\begin{array}{r}\text { Other psychiatric disorder } \\
(n=100)\end{array}$ & $\begin{array}{r}\% \text { of } \\
100\end{array}$ & $\begin{array}{r}\text { Dissociative disorder } \\
(n=16)\end{array}$ & $\begin{array}{r}\% \text { of } \\
16\end{array}$ \\
\hline 0 & No-one & 33 & $28 \%$ & 33 & $33 \%$ & 0 & $0 \%$ \\
\hline 1 & Biological parent/s & 52 & $45 \%$ & 42 & $42 \%$ & 10 & $63 \%$ \\
\hline 2 & Next degree biological relative/s & 11 & $9 \%$ & 8 & $8 \%$ & 3 & $19 \%$ \\
\hline 3 & Biological sibling/s & 8 & $7 \%$ & 7 & $7 \%$ & 1 & $6 \%$ \\
\hline 4 & Intimate partner & 6 & $5 \%$ & 5 & $5 \%$ & 1 & $6 \%$ \\
\hline 5 & Friend/s or family friend/s & 4 & $4 \%$ & 4 & $4 \%$ & 0 & $0 \%$ \\
\hline 6 & Community member/s & 1 & $1 \%$ & 1 & $1 \%$ & 0 & $0 \%$ \\
\hline 7 & Step-parent/s & 1 & $1 \%$ & 0 & $0 \%$ & 1 & $6 \%$ \\
\hline \multirow[t]{2}{*}{8} & Step-sibling/s & 0 & $0 \%$ & 0 & $0 \%$ & 0 & $0 \%$ \\
\hline & Emotional abuse by: & All participants $(N=116)$ & $\%$ of 116 & $\begin{array}{r}\text { Other psychiatric disorder } \\
(n=100)\end{array}$ & $\begin{array}{r}\% \text { of } \\
100\end{array}$ & $\begin{array}{r}\text { Dissociative disorder } \\
(n=16)\end{array}$ & $\begin{array}{r}\% \text { of } \\
16 \\
\end{array}$ \\
\hline 0 & No-one & 29 & $25 \%$ & 29 & $29 \%$ & 0 & $0 \%$ \\
\hline 1 & Biological parent/s & 39 & $34 \%$ & 34 & $34 \%$ & 5 & $31 \%$ \\
\hline 2 & Friend/s or family friend/s & 12 & $10 \%$ & 10 & $10 \%$ & 2 & $13 \%$ \\
\hline 3 & Next degree biological relative/s & 11 & $10 \%$ & 9 & $9 \%$ & 2 & $12 \%$ \\
\hline 4 & Intimate partner & 10 & $9 \%$ & 7 & $7 \%$ & 3 & $19 \%$ \\
\hline 5 & Biological sibling/s & 7 & $6 \%$ & 7 & $7 \%$ & 0 & $0 \%$ \\
\hline 6 & Step-parent/s & 4 & $3 \%$ & 2 & $2 \%$ & 2 & $13 \%$ \\
\hline 7 & Community member/s & 3 & $3 \%$ & 2 & $2 \%$ & 1 & $6 \%$ \\
\hline 8 & Step-sibling/s & 1 & $0 \%$ & 0 & $0 \%$ & 1 & $6 \%$ \\
\hline
\end{tabular}




\begin{tabular}{rrr}
$\begin{array}{r}\text { \% } \boldsymbol{f} \\
\mathbf{1 0 0}\end{array}$ & $\begin{array}{r}\text { Dissociative disorder } \\
(\boldsymbol{n}=\mathbf{1 6})\end{array}$ & $\begin{array}{r}\boldsymbol{\%} \text { of } \\
\mathbf{1 6}\end{array}$ \\
\hline $50 \%$ & 3 & $19 \%$ \\
$18 \%$ & 5 & $32 \%$ \\
$9 \%$ & 3 & $19 \%$ \\
$8 \%$ & 1 & $6 \%$ \\
$5 \%$ & 1 & $6 \%$ \\
$5 \%$ & 0 & $0 \%$ \\
$4 \%$ & 1 & $6 \%$ \\
$1 \%$ & 1 & $6 \%$ \\
$0 \%$ & 1 & $6 \%$
\end{tabular}

1 Biological parent/s

2 Intimate partner

3 Friend/s or family friend/s

Biological sibling/s

5 Next degree biological relative/s

6 Step-parent/s

7 Community member/s

8 Step-sibling/s $(N=116)$

Other psychiatric disorder
$(n=100)$
$(n=100)$

$46 \%$
$20 \%$

$20 \%$

$10 \%$

$8 \%$

$5 \%$

$4 \%$

$4 \%$
$4 \%$
$2 \%$

$2 \%$
$1 \%$

$0 \%$

$6 \%$

Sexual harassment by:

All participants \% of 116 Other psychiatric disorder $(N=116)$

$65 \%$
$10 \%$
$7 \%$
$6 \%$
$4 \%$
$3 \%$
$2 \%$
$3 \%$
$0 \%$
$(n=100)$

$\%$ of 100

Dissociative disorder $\%$ of

0 No-one

75

68

1 Community member/s

2 Next degree biological relative/s

3 Friend/s or family friend/s

4 Biological parent/s

5 Step-parent/s

6 Biological sibling/s

7 Intimate partner

8 Step-sibling/s

All participants $\%$ of 116 Other psychiatric disorder $(N=116)$ $(n=100)$

$68 \%$ $(n=16)$ 16

$9 \% \quad 3 \quad 18 \%$

$6 \% \quad 2 \quad 13 \%$

$6 \%$

$4 \%$

$4 \%$

$2 \%$

$1 \%$

$0 \%$

$6 \%$

$6 \%$

$0 \%$

$0 \%$

$13 \%$

Sexual abuse by:

\begin{tabular}{rr} 
116) & \% of 116 \\
\hline 64 & $55 \%$ \\
15 & $13 \%$ \\
10 & $9 \%$ \\
10 & $9 \%$ \\
7 & $6 \%$ \\
4 & $3 \%$ \\
3 & $2 \%$ \\
2 & $2 \%$ \\
1 & $1 \%$
\end{tabular}

$\%$ of

Dissociative disorder $\%$ of

\begin{tabular}{rrrr}
$\mathbf{1 0 0})$ & $\mathbf{1 0 0}$ & $(\boldsymbol{n = 1 6})$ & $\mathbf{1 6}$ \\
\hline 57 & $57 \%$ & 7 & $44 \%$ \\
12 & $12 \%$ & 3 & $19 \%$ \\
10 & $10 \%$ & 0 & $0 \%$ \\
8 & $8 \%$ & 2 & $13 \%$ \\
6 & $6 \%$ & 1 & $6 \%$ \\
2 & $2 \%$ & 2 & $12 \%$ \\
3 & $3 \%$ & 0 & $0 \%$ \\
2 & $2 \%$ & 0 & $0 \%$ \\
0 & $0 \%$ & 1 & $6 \%$ \\
& & & \\
\hline
\end{tabular}

$(n=16)$

16

1 Community member/s

2 Friend/s or family friend/s

3 Next degree biological relative/s

4 Biological parent/s

5 Intimate partner

6 Step-parent/s

7 Biological sibling/s

8 Step-sibling/s 
TABLE 3: Abuser relation as predictor of dissociative disorder diagnosis in various forms of maltreatment (TEC data) $(\mathrm{N}=116)$

\begin{tabular}{|c|c|c|c|c|c|c|c|c|}
\hline & & $\begin{array}{r}\text { All participants } \\
(N=116)\end{array}$ & $\%$ of 116 & $\begin{array}{r}\text { Other psychiatric disorder } \\
(n=100)\end{array}$ & $\begin{array}{r}\% \text { of } \\
100 \\
\end{array}$ & Dissociative disorder $(n=16)$ & $\%$ of 16 & Logit Model (p) \\
\hline & \multicolumn{8}{|l|}{ Emotional neglect: } \\
\hline 1 & Biological relatives & 70 & $60 \%$ & 56 & $56 \%$ & 14 & $88 \%$ & \\
\hline \multirow[t]{2}{*}{2} & Intimate partner & 6 & $5 \%$ & 5 & $5 \%$ & 1 & $6 \%$ & 0.8442 \\
\hline & Emotional abuse: & & & & & & & \\
\hline 1 & Biological relatives & 54 & $47 \%$ & 49 & $49 \%$ & 5 & $31 \%$ & \\
\hline \multirow[t]{2}{*}{2} & Intimate partner & 11 & $10 \%$ & 7 & $7 \%$ & 4 & $25 \%$ & $0.0278 *$ \\
\hline & Physical abuse: & & & & & & & \\
\hline 1 & Biological relatives & 34 & $29 \%$ & 28 & $28 \%$ & 6 & $38 \%$ & \\
\hline \multirow[t]{2}{*}{2} & Intimate partner & 11 & $10 \%$ & 8 & $8 \%$ & 3 & $19 \%$ & 0.4912 \\
\hline & Sexual harassment: & & & & & & & \\
\hline 1 & Biological relatives & 15 & $13 \%$ & 12 & $12 \%$ & 3 & $19 \%$ & \\
\hline \multirow[t]{2}{*}{2} & Intimate partner & 2 & $2 \%$ & 1 & $1 \%$ & 1 & $6 \%$ & 0.3725 \\
\hline & Sexual abuse: & & & & & & & \\
\hline 1 & Biological relatives & 19 & $16 \%$ & 16 & $16 \%$ & 3 & $19 \%$ & \\
\hline 2 & Intimate partner & 2 & $2 \%$ & 1 & $1 \%$ & 1 & $6 \%$ & 0.2795 \\
\hline
\end{tabular}

* Statistically significant at the 0.05 level 
Fisher's exact tests gave the same statistical results when biological relatives were divided into biological parents and other (non-parental) biological relatives.

Fisher's exact tests compared TEC trauma area presence scores between DD and non-DD patients. Emotional neglect was strongly associated with a DD diagnosis $(\mathrm{p}=0.003$, Table 4). Bodily threat and sexual harassment also associated significantly with a DD diagnosis $(\mathrm{p}<0.05)$ while emotional abuse has moderate evidence of association with a DD $(\mathrm{p}<0.10)$.

Fisher's exact tests compared TEC individual items for different abuser relations between DD and non-DD patients. The individual TEC items relating to the trauma area presence scores are arranged according to the different types of abuse (while allowing for the combination of abusive and non-abusive experiences under 'bodily threat') (Table 4). DD patients had higher frequencies $(\mathrm{p}<0.001)$ of "emotional neglect (e.g., being left alone, insufficient affection) by your [biological] parents, brothers or sisters" than non-DD patients. DD patients had higher frequencies of emotional neglect $(\mathrm{p}=0.039)$, emotional abuse $(\mathrm{p}=0.049)$ and sexual harassment $(\mathrm{p}=0.035)$ by more distant (biological) relatives than non-DD patients (Table 4). DD patients had higher frequencies of sexual harassment $(\mathrm{p}=0.023)$ by non-family members than non-DD patients (Table 4).

More complex logit analyses assessing multiple predictors for abuser relation categories and the probability of a DD diagnosis could not be performed due to the sparseness of the data. 
TABLE 4: Comparison of frequencies of types of abuse between patients with and without dissociative disorders $(\mathrm{N}=116)$

\begin{tabular}{|c|c|c|c|c|c|c|}
\hline & & $\begin{array}{r}\text { Other } \\
\text { psychiatric } \\
\text { disorder } \\
(n=100)\end{array}$ & $\begin{array}{r}\% \text { of } \\
100\end{array}$ & $\begin{array}{r}\text { Dissociat- } \\
\text { ive } \\
\text { disorder } \\
(n=16)\end{array}$ & $\%$ of 16 & $\begin{array}{l}\text { Fisher's } \\
\text { Exact } \\
\text { Test }(p)\end{array}$ \\
\hline \multicolumn{7}{|c|}{ TEC trauma area presence scores: ${ }^{1}$} \\
\hline & Emotional neglect & 64 & $64 \%$ & 16 & $100 \%$ & $0.003 * *$ \\
\hline & Bodily threat $^{2}$ & 85 & $85 \%$ & 16 & $100 \%$ & $0.026 *$ \\
\hline & Sexual harassment & 33 & $33 \%$ & 9 & $56 \%$ & $0.029 *$ \\
\hline & Emotional abuse & 75 & $75 \%$ & 15 & $94 \%$ & 0.068 \\
\hline & Sexual abuse & 45 & $45 \%$ & 9 & $56 \%$ & 0.125 \\
\hline \multicolumn{7}{|c|}{ TEC individual items endorsed: ${ }^{3}$} \\
\hline Item $14 \mathrm{a}$ & Emotional neglect by parents/brother/sister & 53 & $53 \%$ & 16 & $100 \%$ & $<0.001 * *$ \\
\hline Item $15 \mathrm{a}$ & Emotional neglect by more distant relatives & 24 & $24 \%$ & 8 & $50 \%$ & $0.039 *$ \\
\hline Item $16 \mathrm{a}$ & Emotional neglect by non-family members & 39 & $39 \%$ & 10 & $63 \%$ & 0.103 \\
\hline Item $22 \mathrm{a}$ & Physical abuse by non-family members & 31 & $31 \%$ & 9 & $56 \%$ & 0.086 \\
\hline Item $23 \mathrm{a}$ & Bizarre punishment & 19 & $19 \%$ & 6 & $38 \%$ & 0.109 \\
\hline Item $10 \mathrm{a}$ & Intense pain & 53 & $53 \%$ & 12 & $75 \%$ & 0.113 \\
\hline Item $20 \mathrm{a}$ & Physical abuse by parents/brother/sister & 30 & $30 \%$ & 7 & $44 \%$ & 0.386 \\
\hline Item $21 \mathrm{a}$ & Physical abuse by more distant relatives & 11 & $11 \%$ & 3 & $19 \%$ & 0.408 \\
\hline Item $9 \mathrm{a}$ & Threat to life & 43 & $43 \%$ & 9 & $56 \%$ & 0.419 \\
\hline Item $26 \mathrm{a}$ & Sexual harassment by non-family members & 22 & $22 \%$ & 8 & $50 \%$ & $0.023^{*}$ \\
\hline Item $25 \mathrm{a}$ & Sexual harassment by more distant relatives & 11 & $11 \%$ & 5 & $31 \%$ & $0.035^{*}$ \\
\hline Item $24 \mathrm{a}$ & Sexual harassment by parents/brother/sister & 9 & $9 \%$ & 2 & $13 \%$ & 0.635 \\
\hline Item $18 \mathrm{a}$ & Emotional abuse by more distant relatives & 21 & $21 \%$ & 7 & $44 \%$ & $0.049 *$ \\
\hline Item $19 \mathrm{a}$ & Emotional abuse by non-family members & 44 & $44 \%$ & 11 & $69 \%$ & 0.051 \\
\hline Item $17 \mathrm{a}$ & Emotional abuse by parents/brother/sister & 55 & $55 \%$ & 12 & $75 \%$ & 0.176 \\
\hline Item $29 a$ & Sexual abuse by non-family members & 33 & $33 \%$ & 9 & $56 \%$ & 0.081 \\
\hline Item $28 \mathrm{a}$ & Sexual abuse by more distant relatives & 13 & $13 \%$ & 4 & $25 \%$ & 0.233 \\
\hline Item $27 \mathrm{a}$ & Sexual abuse by parents/brother/sister & 13 & $13 \%$ & 2 & $13 \%$ & 1.0 \\
\hline
\end{tabular}

\footnotetext{
${ }^{1}$ TEC trauma area presence scores: These scores represent a count of different types of abuse.

${ }^{2}$ Bodily threat: The score for this trauma area subsumes not only a count of physical abuse experiences, but also a count of non-abusive traumatic experiences including threat to one's life, intense pain or bizarre punishment.

${ }^{3}$ The list of individual TEC items reported here includes only the items of abuse and the three items that are included in the scale's defined score for bodily threat alongside the physical abuse items (i.e., threat to one's life, intense pain and bizarre punishment).

* statistically significant at the 0.05 level

** statistically significant at the 0.01 level
} 


\section{DISCUSSION}

\section{Childhood emotional neglect by biological parents/siblings}

Self-reported emotional neglect was most strongly associated with a diagnosis of a DD in our study. All patients with a DD reported emotional neglect, most frequently perpetrated by biological parents. When individual TEC items were analysed, we identified "emotional neglect (e.g., being left alone, insufficient affection) by your parents, brothers or sisters" as the strongest individual predictor of a diagnosis of a DD.

Our findings support earlier studies that suggest an abuser-abused relational tie of a close biological relative (parent or sibling) might be the greatest risk factor associated with developing a DD (Plattner et al., 2003; Simeon et al., 2001). The findings reported here support Freyd's (1994) betrayal trauma theory. The betrayal of trust that occurs when child victims are abused by their primary carers is considered pivotal in the pathogenesis of DDs (Freyd, 1994, 1997; Haferkamp et al., 2015; Schultz et al., 2003).

These results were obtained from a self-report questionnaire, completed by people suffering from a DD and other non-DD psychiatric disorders. Patients diagnosed with DD may possibly dissociate from other forms of abuse that could have even greater traumatic impact. This abuse would then be under-reported. The high frequency of abuse and high scale scores (Table 2) indicate clear differences between DD and nonDD patients. Emotional neglect and emotional abuse were the most reported forms of abuse by DDs patients, thus possibly exaggerating the strength of their predictive roles.

\section{Later emotional abuse by intimate partners}

This study found a strong association between emotional abuse by an intimate partner and the diagnosis of a DD. Where emotional neglect by biological relatives may be a 
childhood phenomenon, emotional abuse by an intimate partner is often an adult or teenage phenomenon. The TEC records traumatic experiences during the respondent's entire lifetime. Identifying different perpetrators usually indicates abuse during specific life stages even though no differentiation is made between childhood abuse and abuse during adulthood. Intimate partners were more frequently recorded as perpetrators of emotional abuse in patients with a DD than biological parents or other biological relatives. More recent memories of adult emotional abuse by intimate partners could possibly dominate older memories of childhood emotional abuse while the TEC was being completed.

DD patients reporting that intimate partners are the most frequent perpetrators of emotional abuse do not detract from the traumatic childhood etiology of DDs. High frequencies of emotional abuse perpetrated by intimate partners may lend support to Sach's concept of a vicious cycle of DDs, attachment and ongoing abuse. Severe early (childhood) abuse may activate both a passive dissociative reaction and an active attachment reaction, both of which may contribute to (adult) situations of repeated abuse as time goes on (Sachs, 2013). Emotional abuse by intimate partners might not be the cause of the DD, but this is how it often turns out for adult patients with a DD. The fact that emotional abuse was self-reported, may exaggerate its predictive role.

\section{Conflation of information in, and scoring of the TEC}

The conflation of information regarding abuse types and the abuser-abused relational tie in the individual items of the TEC, as well as the confounding of information in the trauma area presence scores of the TEC complicated the analyses of the TEC data.

We addressed these issues by returning to the raw data of the TEC. MuellerPfeiffer et al. (2013) followed a different approach by devising a new scoring system in 
their German adaptation of the TEC (Schumacher et al., 2011). Mueller-Pfeiffer et al. (2013) also parsed out early life stress and adult life stress separately in an attempt to circumvent the TEC's conflation of various life stages in the original design of the scale.

Our study differs further from the Mueller-Pfeiffer et al. (2013) study in that their study used the 8-item DES Taxon for measuring pathological dissociation, whereas our study distinguished between DD and non-DD patients. Our study was limited by the diagnostic distinction and the resultant small subgroup of patients with a DD. The small sample limited the statistical analyses but differentiating between the groups had the benefit of emphasizing the clinical relevance of the findings.

Mueller-Pfeiffer et al.'s (2013) study did not find a relationship between the development of dissociative symptoms after childhood maltreatment and developmental stage or family context at the time of maltreatment. Their study found a strong association between peri-/extra-familial maltreatment and dissociative symptoms. In contrast, our study offers support for both an early childhood etiology of the DDs and subsequent maladaptive cycles of abuse in adulthood. Conflation of different kinds of data may have been an issue in Mueller-Pfeiffer et al.'s study (2013). Our approach of returning to the raw data of the TEC has possibly allowed for the clear emergence of two separate scenarios.

\section{Additional limitations}

This study was limited by sample size. The scales used here and in the broader project took some time to administer, and a limited number of 116 participants could be recruited. Of the 116 patients that took part in the study, a clinically significant proportion of patients were diagnosed with DD (13.8\%). This proportion's relatively 
small size in comparison with the rest of the patients with other psychiatric disorders constrained the statistical analyses and resulted in low statistical power, especially when the subsets of the different abuse types were considered. The relatively small subgroup of patients with a DD also contributed to the logit models' and logistic regression analyses' not reaching a solution. Even though mixed psychiatric samples have several benefits (see also Simeon et al., 2001), the proportion of patients with a DD in such mixed psychiatric samples will always remain relatively small in statistical terms, which would inhibit and/or complicate any predictive analyses.

The logit models with accompanying cross-tabulations and Fisher's exact tests used in this study did contribute useful information, supporting the widely accepted theory that complex, chronic, relational early childhood abuse leads to the development of DDs, while at the same time helping to interpret how adult abuse fits into the picture.

\section{Future research directions and clinical implications}

Future research might benefit from the use of alternative scales that measure childhood traumatic events, e.g., the Childhood Trauma Questionnaire / CTQ (Bernstein et al., 2003), although even the CTQ purportedly has problems of a psychometric nature (Haferkamp et al., 2015). Future development of scales of childhood maltreatment and other traumatic experiences should differentiate clearly between the different types of maltreatment, the ages of the victim at the time of each type of maltreatment, and the perpetrator/s of each type of maltreatment separately, at that specific time - and should allow for all possible permutations. Such refinement will enhance the clinical applicability of studies such as ours.

Health- and other professionals who encounter children or adolescents, should be especially vigilant to recognize the presence of emotional neglect by biological 
parents or close biological relatives. Emotional neglect may be inter-linked with other types of abuse and children who suffer in this way may be at high risk of developing a DD. Such children should be referred for a full assessment for the presence of a DD and given the appropriate treatment as needed. Likewise, mental health professionals who assess or treat adult psychiatric patients should enquire about a childhood history of emotional neglect by their biological parents or close biological relatives, as part of the routine enquiry about a history of childhood maltreatment. Enquiring about adult emotional abuse by intimate partners might also assist in screening for DDs among adults.

\section{CONCLUSIONS AND RECOMMENDATIONS}

DD patients reportedly experienced more abuse than patients without DDs. Two combinations of abuse type and abuser-abused relational tie predicted a DD: childhood emotional neglect by biological parents or siblings, as well as later emotional abuse by intimate partners.

These findings support the early childhood etiology of the DDs, i.e., that complex, chronic, relational early childhood abuse leads to the development of DDs. At the same time, these findings help us to interpret how adult abuse fits into the picture, by lending support to the concept of subsequent maladaptive, attachment-based cycles of abuse in adulthood.

A childhood history of emotional neglect by biological parents or siblings should form a part of the routine enquiry about a history of childhood maltreatment. Enquiring about adult emotional abuse by intimate partners might also assist in screening for DDs among adults. 


\section{ACKNOWLEDGEMENTS}

The authors are grateful to Mrs J Sommerville of the Department of Statistics, University of Pretoria for her assistance with electronic data management and statistical analyses; to Mr BB Versfeld, Ms R Liprini and Ms L Meiring (research assistants in the Department of Psychiatry, University of Pretoria) for their assistance with questionnaire-based data collection and data management; to Dr C Tosh for language editing; and to the patients for their willingness to participate in this research study.

\section{FUNDING}

This research was funded by grants from the South African National Research Foundation, as well as the Department of Psychiatry and Faculty of Health Sciences of the University of Pretoria.

\section{DECLARATION OF INTEREST}

There are no conflicts of interest.

\section{REFERENCES}

American Psychiatric Association (APA). (2013). Diagnostic and Statistical Manual of Mental Disorders, 5th ed. (DSM-5). Washington DC, USA: American Psychiatric Association.

Bernstein, E.M., \& Putnam, F.W. (1986). Development, reliability, and validity of a dissociation scale. Journal of Nervous and Mental Disease, 174(12), 727-735.

Bernstein, D.P., Stein, J.A., Newcomb, M.D., Walker, E., Pogge, D., Ahluvalia, T., Stokes, J., Handelsman, L., Medrano, M., Desmond, D., \& Zule, W. (2003). Development and validation of a brief screening version of the Childhood Trauma Questionnaire. Child Abuse \& Neglect, 27, 169-190.

Carlson, E.B., \& Putnam, F.W. (1993). An update on the Dissociative Experiences Scale. Dissociation, VI(1), 16-27. 
Dalenberg, C.J., Brand, B.L., Gleaves, D.H., et al. (2012). Evaluation of the evidence for the trauma and fantasy models of dissociation. Psychol Bull, 138, 550-88.

Dell, P.F. (2006). The Multidimensional Inventory of Dissociation (MID): A comprehensive measure of pathological dissociation. Journal of Trauma \& Dissociation, 7(2), 77-106.

Dorahy, M.J., \& Van der Hart, O. (2007). Relationship between trauma and dissociation: A historical analysis. In E. Vermetten, M.J. Dorahy, D. Spiegel. (Eds.). Traumatic dissociation: Neurobiology and treatment (pp. 3-30). Washington, DC, USA: American Psychiatric Publishing, Inc.

Dorahy, M.J., Brand, B.L., Şar, V., Krüger, C., Stavropoulos, P., Martínez-Taboas, A., Lewis-Fernández, R., \& Middleton, W. (2014). Dissociative Identity Disorder: An empirical overview. Australian and New Zealand Journal of Psychiatry, 48(5), 402-417. (DOI: 10.1177/0004867414527523).

Farley, M., \& Keaney, J.C. (1997). Physical symptoms, somatization, and dissociation in women survivors of childhood sexual assault. Women \& Health, 25(3), 33-45. (DOI: 10.1300/J013v25n03_03).

Freyd, J.J. (1994). Betrayal trauma: Traumatic amnesia as an adaptive response to childhood abuse. Ethics \& Behavior, 4, 307-329.

Freyd, J.J. (1997). Betrayal trauma: Traumatic amnesia as an adaptive response to childhood abuse. Cambridge, MA: Harvard University Press.

Haferkamp, L., Bebermeier, A., Möllering, A., \& Neuner, F. (2015). Dissociation is associated with emotional maltreatment in a sample of traumatized women with a history of child abuse. Journal of Trauma \& Dissociation, 16(1), 86-99. (DOI: 10.1080/15299732.2014.959149).

Israel, E., \& Stover, C. (2009). Intimate partner violence: The role of the relationship between perpetrators and children who witness violence. Journal of Interpersonal Violence, 24(10), 17551764.

Kilic, O., Sar, V., Taycan, O., Aksoy-Poyraz, C., Erol, T.C., Tecer, O., Emul, M.H., \& Ozmen, M. (2014). Dissociative depression among women with fibromyalgia or rheumatoid arthritis, Journal of Trauma \& Dissociation, 15(3), 285-302. (DOI: 10.1080/15299732.2013.844218). 
Krüger, C. (2016). Variations in identity alteration - a qualitative study of experiences of psychiatric patients with dissociative identity disorder. In: A.P. van der Merwe \& V. Sinason (Eds.), Shattered but unbroken: Voices of triumph and testimony (Chapter 6, pp. 133-161). London: Karnac Books.

Mueller-Pfeiffer, C., Moergeli, H., Schumacher, S., Martin-Soelch, C., Wirtz, G., Fuhrhans, C., Hindermann, E., \& Rufer, M. (2013). Characteristics of child maltreatment and their relation to dissociation, posttraumatic stress symptoms, and depression in adult psychiatric patients. The Journal of Nervous \& Mental Disease, 201(6), 471-7.

Nijenhuis, E.R.S. (1999/2004). Somatoform dissociation: Phenomena, measurement, and theoretical issues. New York: WW Norton \& Co.

Ozcetin, A., Belli, H., Ertem, U., Bahcebasi, T., Ataoglu, A., \& Canan, F. (2009). Childhood trauma and dissociation in women with pseudoseizure-type conversion disorder. Nordic Journal of Psychiatry, 63(6), 462-8.

Plattner, B., Silvermann, M.A., Redlich, A.D., Carrion, V.G., Feucht, M., Friedrich, M.H., \& Steiner, H. (2003). Pathways to dissociation: Intrafamilial versus extrafamilial trauma in juvenile delinquents. The Journal of Nervous \& Mental Disease, 191(12), 781-8.

Ross, C.A., Miller, S.D., Bjornson, L., Reagor, P., Fraser, G.A., \& Anderson, G. (1991). Abuse histories in 102 cases of multiple personality disorder. Canadian Journal of Psychiatry - Revue Canadienne de Psychiatrie, 36(2), 97-101.

Sachs, A. (2013). Still being hurt: The vicious cycle of dissociative disorders, attachment, and ongoing abuse. Attachment: New directions in psychotherapy and relational psychoanalysis, 7, 90-100.

Sandberg, D.A. (2010). Adult attachment as a predictor of posttraumatic stress and dissociation. Journal of Trauma \& Dissociation, 11(3), 293-307. (DOI: 10.1080/15299731003780937).

Sar, V., Akyuz, G., Kugu, N., Ozturk, E., \& Ertem-Vehid, H. (2006). Axis I dissociative disorder comorbidity in borderline personality disorder and reports of childhood trauma. Journal of Clinical Psychiatry, 67(10), 1583-1590. 
Sar, V., Akyüz, G., \& Dogan, O. (2007). Prevalence of dissociative disorders among women in the general population. Psychiatry Research, 149, 169-176.

Sar, V., Önder, C., Kilincaslan, A., Zoroglu, S.S., \& Alyanak , B. (2014). Dissociative identity disorder among adolescents: Prevalence in a university psychiatric outpatient unit. Journal of Trauma \& Dissociation, 15(4), 402-419. (DOI: 10.1080/15299732.2013.864748).

Schäfer, I., Harfst, T., Aderhold, V., Briken, P., Lehmann, M., Moritz, S., Read, J., \& Naber, D. (2006). Childhood trauma and dissociation in female patients with schizophrenia spectrum disorders: An exploratory study. The Journal of Nervous \& Mental Disease, 194, 135-138.

Schultz, T., Passmore, J.L., \& Yoder, C.Y. (2003). Emotional closeness with perpetrators and amnesia for child sexual abuse. Journal of Child Sexual Abuse, 12(1), 67-88. (DOI: 10.1300/J070v12n01_04).

Schumacher, S., Martin-Soelch, C., Rufer, M., Pazhenkottil, A.P., Wirtz, G., Fuhrhans, C., Hindermann, E., \& Mueller-Pfeiffer, C. (2011). Psychometric characteristics of the German adaptation of the Traumatic Experiences Checklist (TEC). Psychol Trauma, 4, 338-346.

Simeon, D., Guralnik, O., Schmeidler, J., Sirof, B., \& Knutelska, M. (2001). The role of childhood interpersonal trauma in depersonalization disorder. Am J Psychiatry, 158, 1027-1033.

Steinberg, M. (1994a). Interviewer's guide to the Structured Clinical Interview for DSM-IV Dissociative Disorders - Revised (SCID-D-R) (2nd ed.). Washington, DC: American Psychiatric Press.

Steinberg, M. (1994b). Structured Clinical Interview for DSM-IV Dissociative Disorders - Revised (SCID-D-R). Washington, DC: American Psychiatric Press.

Van der Hart, O., Nijenhuis, E.R.S., \& Steele, K. (2006). The haunted self: Structural dissociation and the treatment of chronic traumatization. New York: Norton.

Vogel, M., Spitzer, C., Kuwert, P., Möller, B., Freyberger, H. J., \& Grabe, H. J. (2009). Association of childhood neglect with adult dissociation in schizophrenic inpatients. Psychopathology, 42, 124130. 
Watson, S., Chilton, R., Fairchild, H., \& Whewell, P. (2006). Association between childhood trauma and dissociation among patients with borderline personality disorder. Australian and New Zealand Journal of Psychiatry, 40, 478-481.

World Health Organization. (1992). The ICD-10 classification of mental and behavioural disorders: Clinical descriptions and diagnostic guidelines. Geneva: World Health Organization. 